\title{
HABITAÇÃO DE INTERESSE SOCIAL, CONGEITO E PROJETO: UMA PROPOSTA PARA MÃE LUIZA/NATAL-RN
}

\section{BEZERRA JUNIOR, FRANCISCO DA ROCHA}

Arquiteto, MsC., Professor Substituto da UFRN; email: arqchicojunior@gmail.com Dissertação desenvolvida no Mestrado Profissional em Arquitetura, Projeto e Meio Ambiente da UFRN Orientador: Prof. Dr. Marcelo Bezerra de Melo Tinôco; Co-orientador: Dr. José Clewton do Nascimento.

\section{RESUMO EXPANDIDO}

O projeto em tela foi resultado das reflexões desenvolvidas na dissertação do Mestrado Profissional em Arquitetura, Projeto e Meio Ambiente da UFRN, tendo como objetivo elaboração de um projeto de habitação de interesse social, utilizando estratégias de flexibilidade, apresentando como universo de estudo o bairro de Mãe Luiza, localizado na Região Administrativa Leste do município de Natal/RN.

É possível observar que a produção habitacional, cada dia mais, se encontra materializada por meio dos interesses do mercado imobiliário, ignorando as necessidades e os anseios dos diferentes usuários, sobretudo as destinadas à população de baixa renda, independentemente do agente promotor, dos mecanismos adotados para a sua produção e das formas de acesso à moradia, continua necessitando, em menor ou maior escala, de realizações concretas que levem a melhorias do desempenho funcional, apontando às necessidades dos moradores e à satisfação destes no contexto da qualidade de vida urbana (ROMERO; ORNSTEIN, 2003).

Verifica-se, ainda, a excessiva padronização dos conjuntos habitacionais no Brasil, tornando as habitações impessoais, o que impossibilita o estabelecimento de relações entre o usuário e a edificação, não havendo uma harmonia na relação ambiente-usuário, fazendo com que o usuário modifique o ambiente, adaptando-o à sua proposta, o que nem sempre é possível, haja vista questões de ordem técnica, econômica e outras, acarretando-lhe prejuízos em diversos níveis.

No desenvolvimento de um projeto de arquitetura existem algumas premissas que são próprias: a definição de um programa arquitetônico a ser identificado e atendido, a um lugar com diferentes condicionantes projetuais que interferem na sua implantação, e uma forma determinada de materializar a proposta (MACIEL, 2003).

Segundo Edson da Cunha Mahfuz (1995), a interpretação de um problema em um projeto de arquitetura pode acontecer de duas maneiras. A primeira acontece de forma mais simples, no qual a interpretação é gerada pelos mesmos elementos da definição, não havendo nenhuma relação com outro elemento externo. De acordo com o autor, esse tipo de procedimento tem gerado "(...) objetos arquitetônicos que servem somente para a satisfação banal de necessidades imediatas, negando toda possibilidade da obra transcender o seu valor pragmático e utilitário" (MAHFUZ, 1995, p.18). O segundo tipo, mais complexo, o "programa interpretado" apresenta um maior número de aspectos do que os primeiramente constatados, havendo a inclusão de elementos extras e modificando alguns aspectos da definição, auxiliando na interpretação e personalização do programa, levando em conta ainda todo o repertório e personalidade do arquiteto, como apontado a seguir:

A interpretação dos dados de um problema é um processo seletivo que hierarquiza os vários aspectos envolvidos, visando criar uma estrutura capaz de relacioná-los entre si, e implica uma mudança de uma atitude analítica e objetiva, para uma atitude de seletividade subjetiva, na qual a própria personalidade e bagagem cultural do arquiteto desempenham um papel central (MAHFUZ, 1995, p.18). 
O autor ressalta a importância de que "toda obra de arquitetura deve possuir um conceito central ao qual todos os outros elementos permanecem subordinados" (MAHFUZ, 1995, p.18). Isso pode ser expresso por meio de uma ideia criativa ou imagem, baseado mais em valores qualitativos do que em quantitativos, voltado mais na síntese do que na análise.

Segundo James C. Snyder e Anthony Catanese (1984), para iniciar qualquer projeto arquitetônico é de fundamental importância à criação de um "ideal" que possa reunir todas as ideias e conjuntos de informações da proposta.

Para Ricardo Manfredi Naveiro (2001), projetar é uma atividade complexa, e os problemas a serem enfrentados pelos projetistas são mal estruturados ou incompletos, não existindo uma definição satisfatória para o projeto. Entretanto, o autor adverte que não deve ser considerado um defeito o fato dos problemas incompletos, mas como uma especialidade das situações enfrentadas pelos projetistas. O autor complementa sua argumentação no que se refere a complexidade do projeto considerando que projetar é uma indefinição inerente a esta atividade, visto que, ao longo do processo de estruturação de um problema de projeto, o projetista toma decisões baseadas no conhecimento que ele possui do problema até aquele momento, sendo muitas vezes incompleto (NAVEIRO, 2001).

Diversos aspectos irão condicionar uma tomada de decisão do projeto, nem sempre com um sentido racional, sejam de caráter técnicos, econômicos e simbólicos, podendo sofrer novas interferências ao longo de todo o processo como, por exemplo, através de experiências vividas e o momento em que se realiza a proposta. Assim, o conceito torna-se um importante instrumento para reunir todas as ideias e informações em um único ideal. Logo, servirá como ponto de partida para a proposta de solução espacial, técnica e que encaminhará a definição do partido arquitetônico, conforme abordado por Carlos Alberto Maciel (2003, s/p), no trecho a seguir:

[...] proponho pensar o conceito como o esforço do arquiteto em compreender, interpretar e transformar os dados pré-existentes do problema arquitetônico, que se constituem em fundamento para seu trabalho: o lugar, o programa, e a construção. Esta abordagem não procura determinar um procedimento lógico e racional que concatenaria uma seqüência de resultados obtidos cientificamente a partir da observação dos condicionantes.

Os condicionantes projetuais, sejam eles correspondentes aos aspectos físicos, ambientais, culturais, bioclimáticos e legais, interferem diretamente nas primeiras decisões do projeto arquitetônico, possibilitando uma compreensão do problema, elencar opções, escolher um caminho, implementar e avaliar a tomada de decisões.

Para uma melhor compreensão do conceito abordado para a proposta, é preciso, antes de tudo, reconhecer e compreender o lugar. A área de intervenção escolhida para implantação do projeto de habitação de interesse social é um terreno localizado na Rua João XXIII, no bairro de Mãe Luiza, Zona Administrativa Leste do município de Natal/RN. A gleba apresenta forma trapezoidal irregular, com área apenas de 2.232,02 m², distante aproximadamente 160 metros da Avenida Senador Dinarte Mariz.

A história de ocupação do bairro de Mãe Luiza se inicia na década de 1940, em uma área dunar com relevante fragilidade ambiental, realizada por migrantes que sofriam pela seca no interior do estado, que, ao se instalarem ali, iniciaram um processo de ocupação e consolidação da área, como lócus de resistência de uma população de baixa renda.

O processo de ocupação do bairro se deu inicialmente na porção leste, próximo ao mar, estando provavelmente ligado com a pesca, na década de 1950, principalmente a partir de 1958 por motivo de uma forte seca que assolou o Estado. Nos anos de 1970, observa-se uma expansão de maneira linear e discreta, com fragmentos de ocupações ocorrendo ao longo da Rua João XXIII e margeando o cordão dunar no sentido norte/sul, sobretudo, pela importância do sistema viário como principal rota de acesso ao bairro e ao processo de implantação da Via Costeira. Os investimentos e intervenções urbanas desenvolvidas em Mãe Luiza, a partir da década de 1980, tornaram-lhe mais vulnerável e mais propícia à especulação imobiliária, fazendo com que houvesse uma maior mobilidade da comunidade e luta pelo espaço. Na década 
de 1990, o bairro já se encontrava consolidado e com uma infraestrutura básica instalada, sendo nesse período regulamentado como Área Especial de Interesse Social por meio da Lei no 4.663 de 31 de julho de 1995, constituindo a primeira AIES regulamentada no município, o que, do ponto de vista da proteção social e direito à ocupação, foi uma grande conquista.

Verificou-se que a comunidade passou por um forte processo de luta e resistência para permanecer na área, principalmente pela pressão do Estado e do setor imobiliário, demostrando uma forte relação dos residentes com o lugar, fator essencial para a tomada de decisões da proposta arquitetônica.

Nesse sentido, o conceito utilizado para a proposta é resultado desse processo de investigação e interpretação das premissas pré-existentes, definido pela ideia de Identidade (s), abordada em três aspectos: social, cultural e visual, e que se encontram sempre em transformação. Segundo Stuart Dias (2003 apud HALL, 1997, p. 10), "a identidade do sujeito pós-moderno é conceptualizada como não tendo uma identidade fixa, essencial ou permanente". Segundo as reflexões desse autor, as identidades estão sempre em processo de formação, de modo que não se pode falar em identidades fixas, inalteradas.

Figura 1 - Painel Conceito da Proposta Projetual

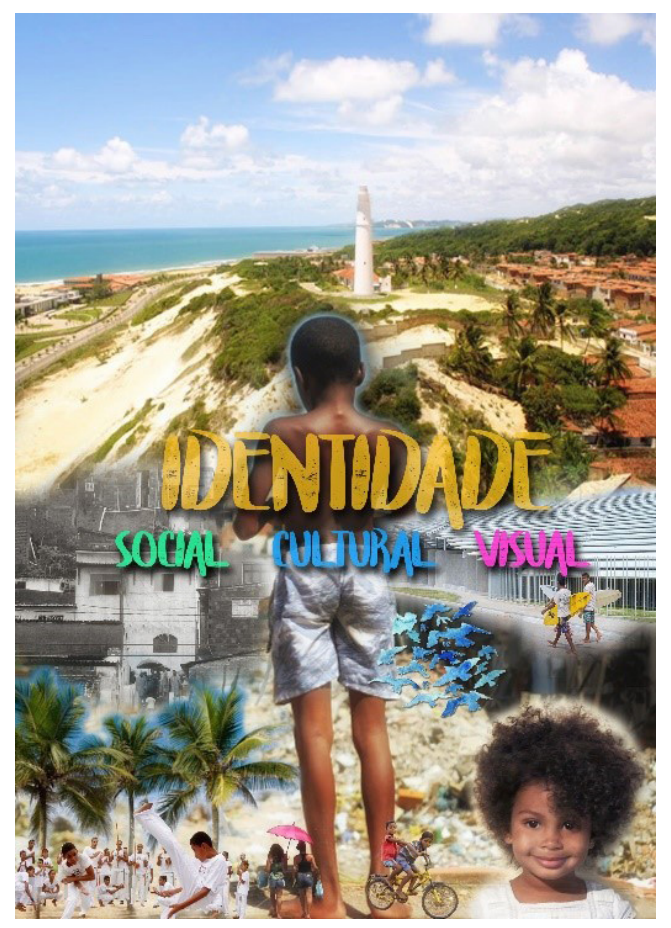

Fonte: Elaborado pelo Autor, 2016

Entende-se como identidade social, para a abordagem em questão, a noção e o sentimento de pertencimento de determinados grupos sociais, tanto no que se refere ao sentido de pertencer ao lugar, como também à edificação. O reconhecimento do caráter de pertencimento da comunidade com o bairro e suas relações sociais vivenciadas foram identificados como elementos essenciais para a ideia proposta, como forma do usuário se sentir parte da proposta arquitetônica e reconhecer espaços para realizações de manifestações e discussões sociais.

Na proposta do conjunto de habitacional, essa ideia foi materializada através da inclusão de espaços de sociabilidade, considerando os diferentes tipos de usuários, não apenas os do conjunto, como também a área de influência do projeto. Nesse sentido, foi realizada uma integração entre o espaço inicial destinado ao conjunto habitacional e o pátio de estacionamento do $4^{\circ}$ Distrito Policial, interligando-os com a escola municipal Antônio Campos. A proposta consiste na criação de uma praça, contendo playground, estacionamentos, paraciclo e academia da terceira idade - ATI. Outro espaço previsto para convivência e lazer é o pátio-vila, funcionando como uma grande área aberta para prática de esporte e socialização, tornando um espaço flexível para diversas atividades da comunidade, reforçando os seus laços afetivos. 
Figura 2 - Espaço de sociabilidade - Praça de convívio

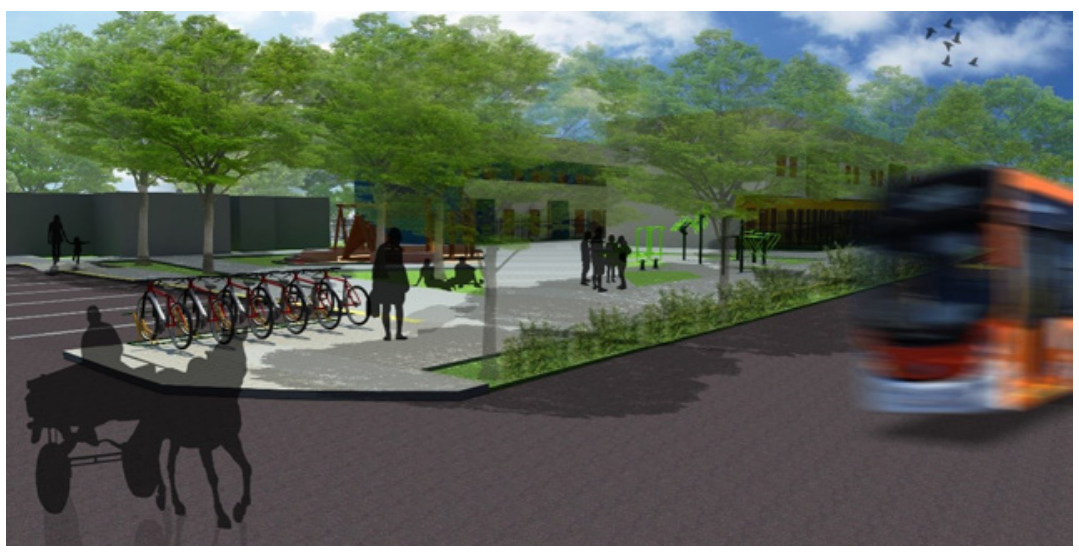

Fonte: Elaborado pelo Autor, 2016

Nas unidades habitacionais, a identidade social é refletida através das estratégias de flexibilidade e adaptabilidade do espaço construído, atendendo inteiramente às necessidades dos diferentes tipos de usuários, assim como através da ideia de filigrana, relação de corpos sólidos, com as edificações ocupando o solo, correlacionando com a fixação ao território, de identidade com a terra, com o lugar, fator significativo para o sucesso de programas habitacionais e relação direta com o conceito do projeto.

O conceito de identidade cultural, para essa análise, está diretamente relacionado aos aspectos culturais, religiosos, sociais, políticos de um determinado lugar. Verifica-se a importância de conhecer e reconhecer as manifestações culturais, a formação e história do lugar e das suas formas de uso e ocupação, sobretudo através das experiências vivenciadas no espaço, conforme defendido por Carlos Alberto Maciel.

Os conceitos, como aqueles que elaboramos durante a produção de um projeto, não surgem do nada, mas da reflexão sobre a nossa própria experiência dos espaços e daquilo que nos fornece a tradição que Ihes concerne. Assim, [...] cumpre elaborar a reflexão sobre nossa experiência desses espaços, sobre a imagem, os significados e sentidos que a tradição nos transmite e que se depositou como repertório da cultura (BRANDÃO, 2000 apud MACIEL, 2003, s/p).

Brunetto et. al (1999 apud LARCHER, 2004, p.1) propõem que a produção em massa da habitação social no Brasil tem desconsiderado questões ligadas à cultura e às características regionais das populações-alvo tendo, como resultado, espaços estranhos para os usuários, com baixa qualidade das edificações e sem possibilidade de flexibilidade, prejudicando as tentativas de adaptação da moradia.

Apesar da ocupação informal, podendo numa primeira análise não haver qualquer tipo de organização, o bairro de Mãe Luiza revela uma organização muito própria com, por exemplo, a relação com que as vias longitudinais procuram vencer os desníveis e as ruas transversais funcionam com caráter essencialmente pedonal, permitindo uma maior apropriação por parte dos usuários, reforçando a relação dos moradores e a comunidade à qual pertencem, e estabelecendo uma maneira própria de usar o espaço, reflexo de sua história de ocupação, sendo parte da identidade do lugar.

Existe uma interdependência clara entre o lote urbano e a arquitetura do edifício, sendo que esta última consegue se adaptar mais facilmente às modificações da cidade do que o lote, que reage de forma mais lenta. É possível identificar, também, diferentes tipologias de agregação, relação espaço público e privado, passíveis de serem identificadas no bairro, com destaque para a linear e radial/pátio, conforme classificação de Sofia Laura Ornelas Neves (2013), como observado na figura 3. 
Figura 3 - Agregação linear do tipo dois lados (A) e um lado (C) pátio/radial de natureza privada (B) e pública (D) no bairro de Mãe Luiza

(A)

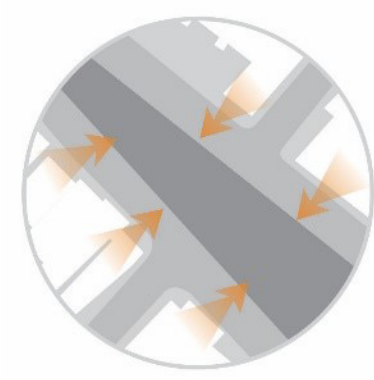

(B)

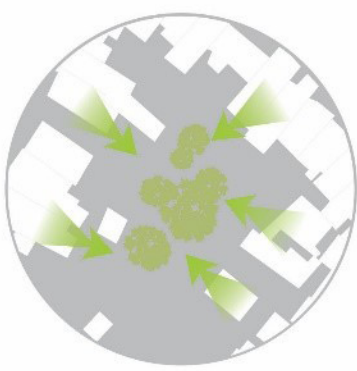

(C)

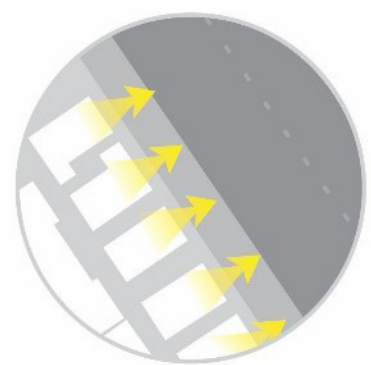

(D)

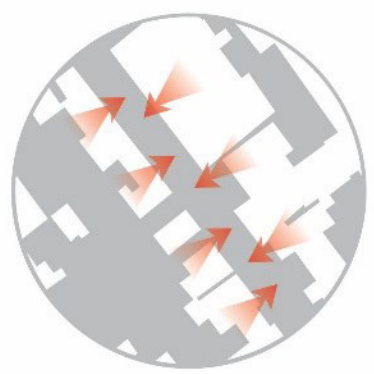

Fonte: Elaborado pelo Autor, 2016

Os sistemas de agregação reforçam, ainda mais, a intensa relação e maneira própria dos moradores de estar e usar os espaços públicos, estabelecendo uma forte identidade e pertencimento com o Bairro, reflexo do seu processo de ocupação e formação.

Outro reflexo do conceito de identidade cultural apresentada na proposta foi a implantação do pátio-vila, possibilidade a manutenção de hábitos existentes no bairro, como o de "conversar na calçada", fazendo do espaço público uma continuação da casa e mantendo os laços culturais e de sociabilidade (Figura 4).

Figura 4 - Pátio-vila como espaço de manifestações culturais e sociabilidade

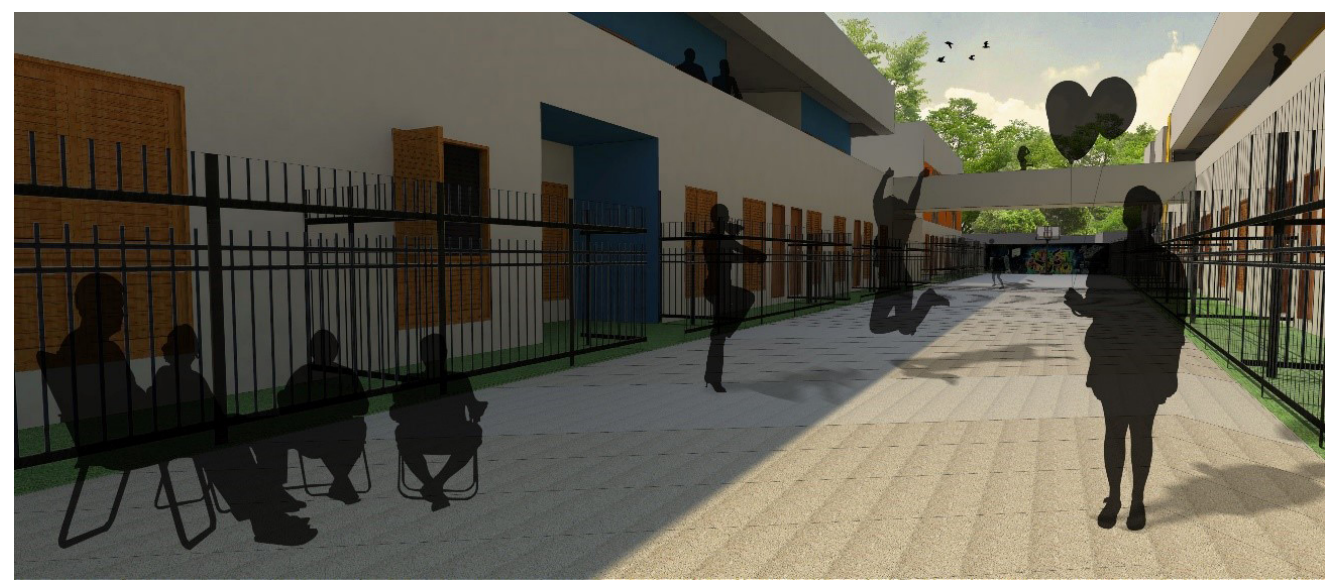

Fonte: Elaborado pelo Autor, 2016

A identidade do tipo visual é caracterizada por um conjunto de elementos formais que representam visualmente, e de forma sistematizada, um nome, uma ideia, um produto. Para o presente trabalho, a identidade visual está associada à tipologia edilícia, à morfologia, aos tipos de materiais empregados nas construções e aos elementos da paisagem do bairro.

Observam-se algumas referências visuais encontradas em Mãe Luiza que influenciaram diretamente na decisão do partido adotado. A primeira identidade visual refere-se ao tipo duplex, presente de maneira significativa em todo bairro. Essa forma está diretamente associada ao tamanho do lote, forma de implantação e necessidade de ampliação ou modificação do uso.

O conjunto apresenta cinco diferentes tipologias residenciais distribuídas nos quatro blocos, possibilitando um maior número de arranjos familiares, atendimento a diferentes necessidades e variedade de estratégias de flexibilidade. O arranjo proposto também possibilitou uma maior liberdade do espaço útil para a livre apropriação, de forma a não condicionar o interior e os ambientes a um único uso, dinamizar a paisagem urbana local através da fachada e refletir a diversidade e pluralidade residencial local. 
Outra referência visual identificada como uma forma de identidade do local são as características morfológicas espaciais do bairro, seu traçado e parcelamento com lotes e quarteirões do tipo "espontâneo/informal", e as relações entre o espaço privado (lote/edificação) e os espaços públicos (rua, praças, etc.), estabelecendo uma ideia de labirinto, tal como definida por Paola Berenstein Jacques (2003). Segundo a autora, essa figura do labirinto sempre aparece nos discursos e imagem das favelas.

Figura 5 - Implantação geral da proposta do Conjunto Residencial

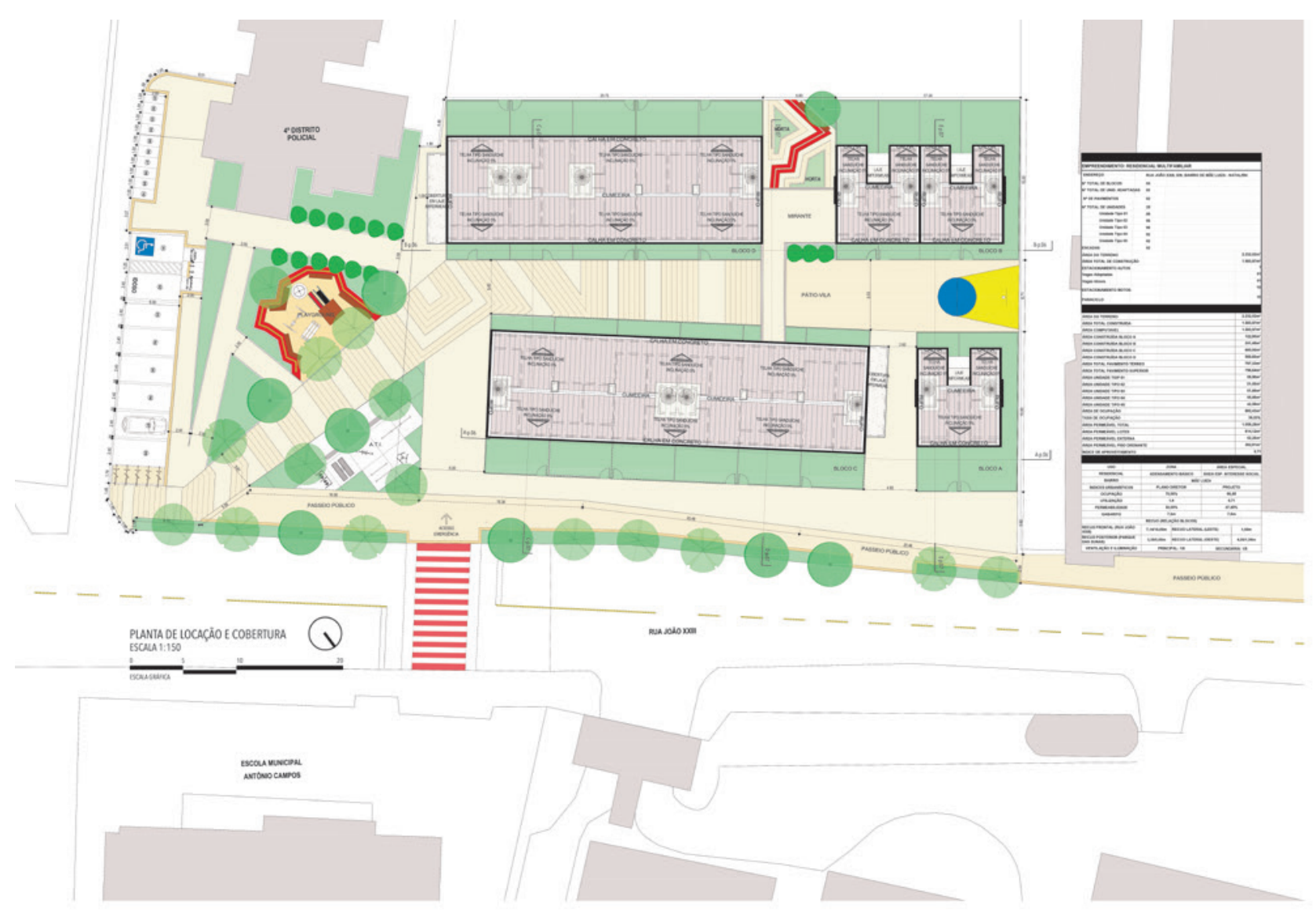

Fonte: Elaborado pelo Autor, 2016

A terceira referência é a ocupação do tipo geminada na qual é compartilhada a estrutura e, em alguns casos, a cobertura das edificações. Essa forma de implantação ocorre sobretudo pela escassez de área do lote, com testada frontal reduzida, impossibilitando a utilização do recuo lateral.

Outra característica visual marcante no bairro são os tipos de materiais construtivos empregados nas edificações. Observa-se uma variedade de materiais, tanto nas vedações, como nos acabamentos. Essa característica reflete diretamente na personalização do lugar, com formas de apropriação e utilização dos materiais, promovendo fachadas diferenciadas. Essa ideia apoia-se no conceito de fragmentos desenvolvido Jacques (2003). As fachadas dos abrigos são fragmentadas formalmente, diferente do interior da construção que é unitário, constituído por um único espaço na maioria das vezes, que, no período da noite, se divide em pequenos compartimentos utilizando cortinas de tecido ou plástico para preservar a intimidade do casal, tornando-se espaços com diversidade de uso (JACQUES, 2003).

Na proposta do conjunto habitacional, a identidade visual foi proposta também através do uso da estratégia de flexibilidade, a qual permite que os moradores imprimam às fachadas e às plantas da edificação, características individuais compatíveis com as necessidades funcionais e com desejos e aspirações, buscando a adaptabilidade às condições de construção e de uso em permanente transformação. 
Figura 6 - Fachada principal do Conjunto Residencial

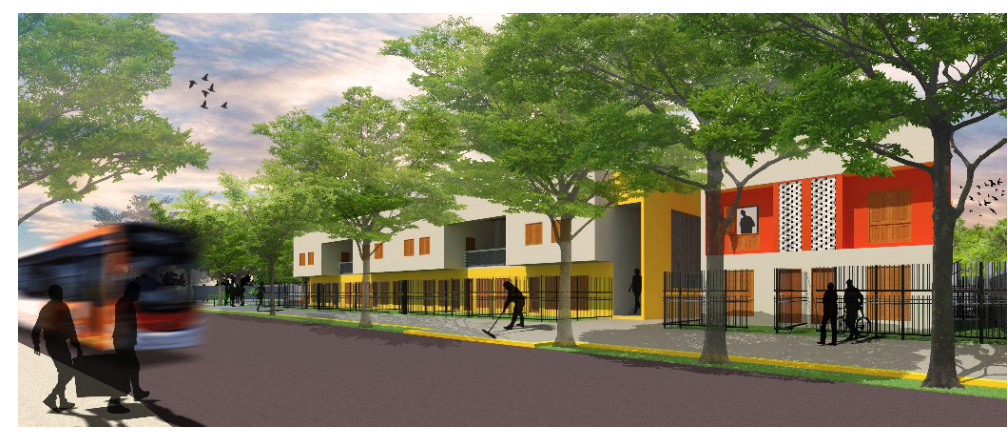

Fonte: Elaborado pelo Autor, 2016

A identidade visual também está associada aos aspectos da paisagem do bairro. Observa-se de maneira clara que a limitação de gabarito, a topografia local e a relação com as características ambientais revelam uma forte relação das edificações com a paisagem local, com destaque para o Parque das Dunas, a praia e o farol de Mãe Luiza. As unidades foram propostas com a altura de 7,50 metros, conforme os condicionantes legais estabelecidos para o bairro, de forma a manter uma relação harmônica com as edificações existentes no bairro, como também com o Parque das Dunas localizado na porção posterior do Conjunto.

Observa-se que conceito de Identidade utilizado na proposta foi o elemento indutor do processo de projeto, caracterizado por Mahfuz, como o "todo conceitual, uma ideia 'forte', um fio condutor em volta do qual a realidade do edifício tomou forma" e materializado no partido (MAHFUZ, 1995, p.19).

Esse "todo conceitual" é mais do que a soma das partes conceituais já que elas são qualificadas e focalizadas pela intencionalidade da operação sintetizadora. A discussão acima sugere uma relação entre as noções de todo conceitual e partido, no sentido em que o primeiro é o embrião do segundo (MAHFUZ, 1995, p.19).

Por fim, o conceito de identidade(s) encontra-se amparado no traçado e parcelamento; na tipologia edilícia e os tipos de uso; na ideia de labirinto e fragmento; no gabarito, os marcos de referência e a relação com a paisagem local, fortalecendo os laços da comunidade com o lugar, influenciando diretamente na proposta final do objeto arquitetônico, e reafirmando os aspectos espaciais e formais tão marcantes e presentes no bairro de Mãe Luiza.

\section{REFERÊNCIAS}

BEZERRA JUNIOR, Francisco da Rocha. HABITAÇÃO SOCIAL EVOLUTIVA: Estratégias de flexibilidade para elaboração de projetos de habitação de interesse social. Uma proposta para Mãe Luiza/Natal-RN. Dissertação de Mestrado apresentada ao Programa de Pós-Graduação em Arquitetura e Urbanismo / Mestrado Profissional em Arquitetura, Projeto e Meio Ambiente. Natal, 2016.

HALL, Stuart. Identidades culturais na pós-modernidade. Rio de Janeiro: DP\&A, 1997.

JACQUES, Paola Berenstein. Estética da ginga: a arquitetura das favelas através da obra de Hélio Oiticica. Rio de Janeiro: Casa da Palavra, 2003.

LARCHER, J.V.M; PEREIRA, A.C.W.; GAIA, S.; SANTOS, A. dos. A incorporação de conceitos das novas filosofias da construção de projetos de habitação de interesse social. In; WORKSHOP BRASILEIRO DE GESTÃO DO PROCESSO DE PROJETO NA CONSTRUÇÃO DE EDIFÍCIOS, 4., 2004, Curitiba. Anais...Curitiba: UFPR, 2004. Disponível em: <http:/hdl.handle.net/1884/3514>33. Acesso em 14 jun. 2015.

MACIEL, Carlos Alberto. Arquitetura, projeto e conceito. Arquitextos, São Paulo, ano 04, n.043.10, Vitruvius, dez. 2003. Disponível em : <http://www.vitruvius.com.br/revistas/read/arquitextos/04.043/633>. Acesso em: 10 abr. 2015.

MAHFUZ, E. Ensaio sobre a razão compositiva. Belo Horizonte: UFV/AP Cultural, 1995.

NAVEIRO, R. M. Conceitos e Metodologias de Projeto. O projeto de engenharia, arquitetura e desenho industrial. Juiz de Fora: UFJF, 2001.

ROMÉRO, M.A; ORNSTEIN, S.W. (Ed,; Coord.) Avaliação pós-ocupação: métodos e técnicas aplicadas à habitação social. Porto Alegre: Antac, 2003 (Coleção Habitare).

SNYDER, James C. e CATANESE, Anthony. Introdução à Arquitetura. Rio de Janeiro: Ed. Campus Ltda., 1984

NOTA DO EDITOR (*) O conteúdo do artigo e as imagens nele publicadas são de responsabilidade do(s) autor(es). 